\title{
Stress-Induced Memory Retrieval Impairments: Different Time-Course Involvement of Corticosterone and Glucocorticoid Receptors in Dorsal and Ventral Hippocampus
}

\author{
R Dorey ${ }^{1,2,3}$, C Piérard ${ }^{2,3}$, F Chauveau ${ }^{2}$, V David' and D Béracochéa*,' \\ 'CNRS; Universités de Bordeaux; Institut de Neurosciences Cognitives et Intégratives d'Aquitaine (INCIA) UMR, Talence, France; ${ }^{2}$ Institut de \\ Recherche Biomédicale des Armées (IRBA) - Unité de Neuropsychopharmacologie Brétigny sur Orge Cedex, France
}

\begin{abstract}
The present study was aimed at determining the relative contribution of the dorsal (DH) and ventral (VH) hippocampus in stressinduced memory retrieval impairments. Thus, we studied the temporal involvement of corticosterone and its receptors, i.e. mineralocorticoid (MR) and glucocorticoid (GR) in the $\mathrm{DH}$ and $\mathrm{VH}$, in relation with the time-course evolution of stress-induced memory retrieval impairments. In a first experiment, double microdialysis allowed showing on the same animal that an acute stress (electric footshocks) induced an earlier corticosterone rise in the $\mathrm{DH}$ ( $15-60$ min post-stress) and then in the VH (90-105 min post-stress). The return to baseline was faster in the $\mathrm{DH}$ ( $105 \mathrm{~min}$ ) than in the $\mathrm{VH}$ ( $120 \mathrm{~min})$. Memory deficits assessed by delayed alternation occurred at 15-, 60-, and 105-min delays after stress and were closely related to the kinetic of corticosterone rises within the DH and $\mathrm{VH}$. In a second experiment, the GR antagonist RU-38486 and the MR antagonist RU-283 8 were administered in the DH or VH I 5 min before stress. RU-38486 restored memory at 60 but not at 105 min post-stress delays in the DH, whereas the opposite pattern was observed in the $\mathrm{VH}$. By contrast, RU-28318 had no effect on memory impairments at both the 60- and 105-min post-stress delays, showing that MR receptors are not involved at these delays. However, RU-28318 administered in the DH restored memory when administered at a shorter post-stress delay ( $15 \mathrm{~min}$ ). Overall, our data are first to evidence that stress induces a functional switch from the $\mathrm{DH}$ to $\mathrm{VH}$ via different corticosterone time-course evolutions in these areas and the sequential GR receptors involvement in the $\mathrm{DH}$ and then in the $\mathrm{VH}$, as regards the persistence of stress-induced memory retrieval deficits over time.

Neuropsychopharmacology (2012) 37, 2870-2880; doi:I0. I038/npp.2012.170; published online 5 September 20I2
\end{abstract}

Keywords: glucocorticoid MR and GR receptors; dorsal and ventral hippocampus; microdialysis; stress; memory-corticosterone

\section{INTRODUCTION}

The dorsal (DH) and ventral (VH) regions of the hippocampus (HPC) are anatomically and functionally distinct areas (Fanselow and Dong, 2010). More specifically, the DH is mainly connected through differential connections with the neocortex, whereas VH is mainly connected with the amygdala and hypothalamus (Moser and Moser, 1998; Naber and Witter, 1998; Segal et al, 2010). On the other hand, the DH would be primarily involved in cognitive processes sustaining learning and spatial memory processes, whereas VH would be associated with motivational and emotional behaviors (Segal et al, 2010).

Glucocorticoids (GCs) primarily act through glucocorticoid receptors (GR) and mineralocorticoid receptors (MR). Both types of receptors are highly co-localized in limbic

* Correspondence: Dr D Béracochéa, CNRS, Universités de Bordeaux; Institut de Neurosciences Cognitives et Intégratives d'Aquitaine (INCIA), UMR CNRS, Univ BordeauxI Bat Biologie Animale, Avenue des faculties, Talence, 5287-33400, France, Tel: +33 540002439, Fax: +33 5 40008743, E-mail: daniel.beracochea@u-bordeauxl.fr ${ }^{3}$ Both authors share the first place in the list of authors.

Received 3 April 2012; revised 25 July 2012; accepted 25 July 2012 structures and particularly within the HPC (De Kloet et al, 1986; Van Eekelen et al, 1988). These two receptor types are, however, differentially distributed in the brain (Reul and de Kloet, 1985). Thus, MR are highly expressed in neurons of the hippocampal formation and the lateral septum and moderately expressed in subnuclei of the amygdala, the hypothalamic paraventricular nucleus, and the locus coeruleus (Joëls et al, 2008). These regions define a circuit that is involved in the cognitive, emotional, and neuroendocrine processing of stressful events (McGaugh, 2004). GR are ubiquitously expressed in the brain, but mainly in the HPC, the lateral septum, and the paraventricular nucleus (Joëls and Baram, 2009). MR receptors have a high affinity for corticosteroids, so they are mostly occupied even when circulating corticosteroid levels are low, whereas GR have tenfold lower affinity and become more occupied as corticosteroid levels increase-for example, after stress (Joëls et al, 2008).

From a functional point of view, steroids can rapidly modulate neuronal activity through a non-genomic pathway via an activation of membrane receptors (Borski, 2000; Falkenstein et al, 2000; Makara and Haller, 2001; Dallman, 2005; Tasker et al, 2006; Groc et al, 2008; Conboy and 
Sandi, 2010) and synaptic excitatory transmission (Pfaff et al, 1971; Chaouloff and Groc, 2011). Steroids also increase the release of excitatory amino acids (Venero and Borrell, 1999). In addition to rapid membrane mechanisms, corticosteroid receptors could also translocate to the nucleus, where they act as regulators of gene transcription (Lu et al, 2006; Revest et al, 2010). Therefore, steroid effects on neuronal function usually require at least $1 \mathrm{~h}$ to develop and last hours to days. In the HPC, MR activation is a prerequisite for maintaining the ongoing information flow, whereas activation of GR - for example, after stress-causes a delayed suppression of neuronal excitability and synaptic plasticity (Joëls et al, 2007; Kim and Diamond, 2002), thus providing 'negative-feedback regulation' of behavioral aspects of the stress response (see Joëls and Baram, 2009).

From a cognitive point of view, it has been shown that GC receptors modulate spatial and non-spatial memory (De Quervain et al, 1998; Kim and Diamond, 2002; Roozendaal, 2003; Ferguson and Sapolsky, 2007). It has been proposed that GR receptors would sustain delayed effects on memory via transcriptional factors (McEwen and Sapolsky, 1995; De Kloet et al, 1999; Sapolsky et al, 2000; Lupien and Lepage, 2001; McGaugh and Roozendaal, 2002; Donley et al, 2005; Joëls et al, 2006; Joëls and Baram, 2009), whereas MR would be primarily involved in the rapid cognitive effects of stress. In particular, it has been shown that MR mediate the corticosterone-induced impairment of memory retrieval (Khaksari et al, 2007). However, the rapid effects of corticosterone on behavior and cognitive processes remain seldom documented (Orchinik et al, 1991; Sandi et al, 1996; Breuner et al, 1998; Sajadi et al, 2006).

We previously showed that acute stress induced a rapid (15 min) corticosterone rise in the $\mathrm{DH}$ associated to memory-retrieval deficits (Chauveau et al, 2010), which specifically implicated MR but not GR receptors via nongenomic membrane mechanisms (Dorey et al, 2011). However, as in our previous study, the memory deficit lasted at least $60 \mathrm{~min}$ after stress, and because one cannot exclude that stress could activate simultaneously both the $\mathrm{VH}$ and $\mathrm{DH}$, we now intend to determine the relative involvement of the $\mathrm{DH}$ and $\mathrm{VH}$ and the GC receptor types in the rapid and delayed effects of stress on memory retrieval.

To these aims, experiment 1 was designed to measure simultaneously in both the $\mathrm{DH}$ and $\mathrm{VH}$ the stress-induced time-course evolution of corticosterone rise after acute stress. In a further step, experiment 2 was designed to determine the involvement of the GC receptors (MR and/or GR) on memory impairments associated with the stressinduced time-course evolution of corticosterone rise in the $\mathrm{DH}$ and/or $\mathrm{VH}$.

\section{MATERIALS AND METHODS}

\section{Experimental Design}

Experiment 1 was designed (i) to test the impact of an acute stress on the time-course evolution of corticosterone rises both in the $\mathrm{DH}$ and $\mathrm{VH}$, measured in the same mouse by microdialysis and (ii) to evaluate the impact of stress on memory retrieval in independent groups of mice at different delays after stress delivery, according to data drawn from the microdialysis experiment.
Experiment 2 was designed to determine the type of GC receptors involved in the delayed $(15,60$, and $105 \mathrm{~min})$ stress-induced memory impairments. These delays were chosen according to the time-course evolution of corticosterone levels observed in the $\mathrm{DH}$ and $\mathrm{VH}$ after stress. The GR antagonist RU-38486 or the MR antagonist RU-28318 were injected into the $\mathrm{DH}$ or $\mathrm{VH} 15 \mathrm{~min}$ before stress delivery and memory was assessed at either 15-, 60-, or 105min post-stress delay intervals.

\section{Animals}

The subjects were 6-month-old male mice of the C57BL/6 inbred strain obtained from Charles Rivers (France). At the time of the experiments, mice weighed between 28 and $32 \mathrm{~g}$. They were housed individually with free access to water on a 12-h light-dark cycle in a temperature-controlled and ventilated room. Tests were conducted during the light phase of the cycle between 0800 and $1200 \mathrm{hrs}$. The number of animals in each group is given in the Results section.

\section{Experiment 1}

Surgery. Mice were anesthetized with a ketamine $(1 \mathrm{mg} / \mathrm{kg}$ body weight)-xylazine ( $10 \mathrm{mg} / \mathrm{kg}$ body weight) solution and placed on a stereotaxic frame. Two microdialysis guide-cannulae (for CMA/7 microdialysis probes, CMA Microdialysis, Sweden) were implanted at the following coordinates from the bregma (Paxinos and Franklin, 2001): for the $\mathrm{DH}: \mathrm{AP}=-2000 \mu \mathrm{m}, \mathrm{L}= \pm 1300 \mu \mathrm{m}$, and $\mathrm{V}=$ $-1000 \mu \mathrm{m}$; for the $\mathrm{VH}: \mathrm{AP}=-3000 \mu \mathrm{m}, \mathrm{L}= \pm 2900 \mu \mathrm{m}$, and $\mathrm{V}=-3000 \mu \mathrm{m})$. The laterality of implantation in the $\mathrm{DH}$ and $\mathrm{VH}$ was randomized as half of the animals were implanted in the right side for the $\mathrm{DH}$ and left side for the $\mathrm{VH}$, whereas the other half were implanted in the opposite way.

Guide-cannulae were fixed with dental cement and three micro screws attached to the skull. All operated mice were allowed to recover in the animals room.

Microdialysis. Microdialysis was performed in freely moving animals to measure corticosterone levels in the $\mathrm{DH}$ and $\mathrm{VH}$ after acute stress. Indeed, in vivo microdialysis is an extremely powerful method to study the highly dynamic neurotransmitter responses in the field of stress physiology and behavior (Linthorst and Reul, 2008; Dorey et al, 2011).

On the day before the experiment, microdialysis probes (CMA/7, membrane length $1 \mathrm{~mm}$; CMA Microdialysis, Sweden) were inserted through the guide-cannulae so that their membranes were lowered $1 \mathrm{~mm}$ below guide-cannulae into the $\mathrm{DH}$ or $\mathrm{VH}$. Probes were continuously perfused with sterile, filtered Dulbecco's solution (mock CSF) at a rate of $0.1 \mu \mathrm{l} / \mathrm{min}$. Equilibration of extracellular concentrations lasted $12 \mathrm{~h}$, i.e., in the night before the test day. After the equilibration phase, baseline dialysates (15-min samples) were collected in the morning with a flow rate of $1 \mu \mathrm{l} / \mathrm{min}$ during $2 \mathrm{~h}$. Then, the acute stress was applied using a footshocks delivery system located in the dialysis cage. The acute stress was constituted by three successive unavoidable electric footshocks $(0.9 \mathrm{~mA} ; 10 \mathrm{~ms})$ in keeping with our previous studies (Chauveau et al, 2010; Dorey et al, 2011). The dialysates were collected during 3 additional hours after 


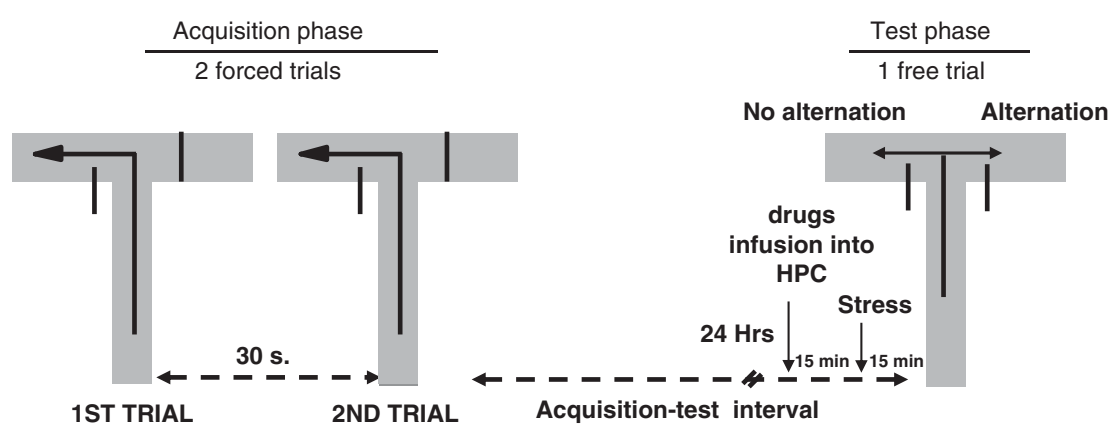

Figure I Memory testing procedure: during a session, animals were first submitted to an acquisition phase in which they were forced to enter twice the same arm of the maze (two forced trials). Then, after a 24-h delay interval, they were submitted to the test phase in which they can freely enter either in the right or in the left arm of the maze. An alternation was scored when the mouse entered the arm opposite to the one visited in the acquisition phase. Treatments (stress and antagonists injections in the $\mathrm{DH}$ and $\mathrm{VH}$ ) were delivered before the test phase, according to the experimental schedule described in the Materials and Methods section.

stress (flow rate: $1 \mu \mathrm{l} / \mathrm{min}$; sampling delay: $15 \mathrm{~min}$ ). Samples were stored at $-80^{\circ} \mathrm{C}$ before analysis. Free corticosterone levels measured in the dialysates were expressed as the percentage of the averaged baseline values.

At the end of the microdialysis experiment, mice were anesthetized and then transcardially perfused in the left ventricle with saline solution $(\mathrm{NaCl} 0.9 \%)$ followed by formaldehyde (4\%). Brains were then post-fixed in a $4 \%$ formaldehyde solution for 10 days, and then in a saccharose-formaldehyde solution $(30-40 \% \mathrm{v} / \mathrm{v})$ for 2 days. All the brains were coronally sectioned $(50 \mu \mathrm{m}$ thickness). A cresyl violet stain was used to check the exactness of the microdialysis probes implantation.

Intra-hippocampal corticosterone assay. An Enzyme Immunoassay commercial kit (Correlate-EIA, Assay Designs, Ann Arbor, USA) was used to measure HPC corticosterone concentrations in the microdialysates. The sensitivity of the assay was $18.6 \mathrm{pg} / \mathrm{ml}$. Therefore, baseline sample concentration was more than 10 -fold above the sensitivity threshold.

Plasma corticosterone assay. Independent groups of mice were used ( 29 mice as a whole). Mice were placed in the footshocks delivery system located in the microdialysis cage, for at least $1 \mathrm{~h}$ before being administered with the electric footschocks used in the microdialysis experiment. After stress, they remained in the microdialysis cage and were decapitated to collect trunk blood after either $15 \mathrm{~min}$ $(N=4), 30 \mathrm{~min}(N=4), 60 \mathrm{~min}(N=4), 90 \mathrm{~min}(N=4)$, $105 \mathrm{~min}(N=4)$, or $120 \mathrm{~min}(N=4)$ post-stress delays. Control animals were submitted to the same experimental conditions but did not receive footshocks $(N=5)$. They were killed $1 \mathrm{~h}$ after being placed in the shock delivery system included in the microdialysis cage. Thus, these animals constitute a 'time 0 ' control group. After centrifugation at 3000 r.p.m. for $10 \mathrm{~min}$, the supernatant was stored at $-80^{\circ} \mathrm{C}$ until ELISA assay (Correlate-EIA, Assay Designs, Ann Arbor, USA).

Acute stress delivery. The same acute stress $(0.9 \mathrm{~mA}$; $10 \mathrm{~ms}$ ) was applied for behavioral experiments. Stress was delivered in a room different from the one used for behavioral testing. Mice remained for $1 \mathrm{~min}$ in a stress delivery cage.
Non-stressed mice were placed in the cage in the same conditions except that they did not receive footshocks.

Behavioral task: delayed alternation procedure. The procedure and methods have been extensively described in a previous study (see Dorey et al, 2011 for detailed information). Memory was evaluated by delayed alternation rate in a T-maze used as an index of memory performance (Figure 1). Testing was conducted between 0800 and $1200 \mathrm{hrs}$, in order to minimize the circadian variations of corticosterone.

In the acquisition phase, the subjects were forced to enter twice the same arm of the maze. The two forced trials were separated by a $30-\mathrm{s}$ interval. The acquisition phase was followed by a test phase implemented $24 \mathrm{~h}$ later. During the test trial, animals remained $30 \mathrm{~s}$ in the start box. The door was then opened, and animals were free to enter into one of the arms of the maze. The correct choice is to enter the arm opposite to that entered the day before. In all the experiments, animals were automatically confined for $30 \mathrm{~s}$ in the chosen arm by the closing of a slide door. Thus, this confinement period was imposed on the animals. The closing of the slide door was automatically triggered by the crossing of photoelectric cells placed at the middle of the arm, requiring that the subject completely entered the chosen arm. Thus, the closing of the door determines the criterion to score the choice of the mouse. The mouse remained $30 \mathrm{~s}$ into the chosen arm before being replaced for $30 \mathrm{~s}$ in the start-box for a subsequent free choice trial. This short-term trial was aimed at determining whether the intrinsic psychomotor ability and motivation of mice to alternate were spared by the treatments, so that any deficits observed at the previous $24 \mathrm{~h}$ test trial cannot be ascribed to either psychomotor or motivational impairments.

Mice were submitted to two forced trials sessions in the same experimental conditions. The blocked arm of the second session was opposite to the one blocked in the first session. Each session was separated by a 1-week period. Thus, each mouse served as its own control to avoid place preference bias in the alternation performance during the test sessions.

The test sessions took place 15,60 , or 105 min after the acute stress administration. 


\section{Experiment 2}

Surgery. Mice were anesthetized with a ketamine $(1 \mathrm{mg} / \mathrm{kg}$ body weigh)-xylazine (10 mg/kg body weight) solution. Stereotaxic coordinates are referenced in $\mu \mathrm{m}$ from the bregma (Paxinos and Franklin, 2001). For pharmacological administration in the $\mathrm{DH}$, two stainless-steel guide cannulae (26 guage, $8 \mathrm{~mm}$ length) were implanted bilaterally $1 \mathrm{~mm}$ above the surface of the $\mathrm{DH}(\mathrm{AP}=-2000 \mu \mathrm{m}$; $\mathrm{L}= \pm 1300 \mu \mathrm{m}$; and $\mathrm{V}=-1000 \mu \mathrm{m})$. For administration in the $\mathrm{VH}$, two stainless-steel guide-cannulae (26 guage, $8 \mathrm{~mm}$ length) were implanted bilaterally at the following coordinates $(\mathrm{AP}=-3000 \mu \mathrm{m} ; \mathrm{L}= \pm 2900 \mu \mathrm{m}$; and $\mathrm{V}=$ $-3000 \mu \mathrm{m})$. Guide-cannulae were fixed in place with dental cement and three micro screws attached to the skull. All operated mice were allowed to recover in the animal room for at least 7 days before behavioral experiments.

Antagonists were injected through two 32-guage stainlesssteel cannulae ( $9 \mathrm{~mm}$ length) attached to a microsyringe with polyethylene catheter tubing. The cannulae were inserted into the guide-cannulae. The syringes were placed in a constant flow rate pump $(0.4 \mu \mathrm{l} / \mathrm{min})$. Corticosterone receptors antagonists (RU-38486 and RU-28318; Tocris, USA) at the concentration of $20 \mathrm{mg} / \mathrm{ml}$ or vehicle (mock CSF additioned with a small amount of absolute ethanol) were bilaterally injected $15 \mathrm{~min}$ before stress delivery in either the $\mathrm{DH}$ or $\mathrm{VH}$. The antagonists were injected in a volume of $0.40 \mu \mathrm{l}$ per side $(0.05 \mu \mathrm{l} / \mathrm{min}$ during $8 \mathrm{~min})$. The choice of these doses was already validated according to the behavioral data described in a previous paper (Dorey et al, 2011). Moreover, we already showed that these MR and GR antagonists at the very same doses have no effects on memory in the same task in nonstressed mice (Dorey et al, 2011).

Experimental animals (i.e. animals receiving the MR or GR antagonists injections) were compared with animals which were implanted with cannulae and received the vehicle solution only, either in stress or non-stress conditions (stressed + vehicle or non-stressed + vehicle groups, respectively).

Behavioral schedule. The behavioral procedure was similar to that of Experiment 1. Behavioral testing occurred $15 \mathrm{~min}$ after stress. Independent groups of mice were tested for three post-stress delays according to the results obtained in Experiment 1 i.e. 15, 60, and $105 \mathrm{~min}$. Mice were submitted to two forced trials sessions with the same antagonist dose and experimental conditions. The blocked arm of the second session was opposite to the one blocked during the first session. Each session was separated by a wash-out period of 1 week. Thus, each mouse served as its own control to avoid place preference biases. After behavioral testing, mice were killed, and their brains were removed and coronally sectioned (50 $\mu \mathrm{m}$ thickness). A cresyl violet stain was used to verify the exact probe location in the $\mathrm{DH}$ and $\mathrm{VH}$.

\section{Statistical analysis}

Statistical analyses were performed using the Statview 5.0 software. In the behavioral experiments, data drawn from the two test sessions were averaged and expressed as means \pm SEM. The data were analyzed using one-way or two-ways factorial analyses of variance (ANOVA) followed, when adequate, by post-hoc comparisons (Bonferroni/ Dunnett test). Comparisons of retrieval performances with chance level were calculated with one sample Student's $t$-test (with hypothesized mean $=$ chance level of $50 \%$ ). Microdialysis data were analyzed using one- or two-ways repeated-measure ANOVA as appropriate, followed when adequate by post-hoc testing (Bonferroni/Dunnett test).

One animal out of 10 in Experiment 1 and 5 animals out of 70 in Experiment 2 were excluded a posteriori from statistical analyses because of inaccurate implantation of cannulae for microdialysis or pharmacological injections.

\section{RESULTS}

1st Experiment: Effects of Acute Stress on Hippocampal and Plasma Corticosterone Concentrations and Delayed Alternation rates.

Stress-induced intra-HPC corticosterone rise. The absolute concentrations of corticosterone in baseline condition are not significantly different between the $\mathrm{DH}$ and $\mathrm{VH}$ $(251.4 \pm 14.1 \mathrm{ng} / \mathrm{l}$ vs $275.0 \pm 14.5 \mathrm{ng} / \mathrm{l}$ respectively; $\mathrm{F}(1,18)=$ $1.35 ; p=0.26$, NS). Figure $2 \mathrm{a}$ represents corticosterone levels in the HPC areas, DH $(n=10)$ and VH $(n=10)$, in which results are expressed in relative concentrations (i.e. as percentage of variation of baseline). Two-way repeatedmeasures ANOVA performed on corticosterone kinetic evidenced a significant interaction between the HPC areas and time $\left(\mathrm{F}_{(14,252)}=2.93 ; p \leq 0.0004\right)$. Thus, the time-course evolutions of corticosterone in the $\mathrm{DH}$ and $\mathrm{VH}$ are overall significantly different.

Intergroup comparisons showed that corticosterone levels in the $\mathrm{DH}$ and $\mathrm{VH}$ significantly differed for $60 \mathrm{~min}$ $(197.4 \pm 24.7$ vs $110.9 \pm 7.5$, respectively; $p<0.05)$ and $105 \mathrm{~min} \quad(103.0 \pm 10.5$ vs $165.0 \pm 19.2 \%$, respectively; $p<0.05)$. Thus, our data show that rise in corticosterone in the $\mathrm{DH}$ appears to be earlier than in the $\mathrm{VH}$.

\section{Dorsal Hippocampus}

As compared with the last pre-stress sample $(97.1 \pm 6.7 \%$; 'time $=0$ '), stress induced a progressive and significant increase in corticosterone levels from $15 \mathrm{~min}$ $(137.6 \pm 20.2 \% ; t=2.30 ; p \leq 0.05)$ to $90 \mathrm{~min}(139.1 \pm 24.1 \%$; $t=2.32 ; p \leq 0.05)$. Furthermore, the highest difference was observed $60 \mathrm{~min}$ after stress administration (197.4 \pm 24.7 ; $t=3.57 ; p \leq 0.01)$.

\section{Ventral Hippocampus}

As compared with the last pre-stress sample $(97.3 \pm 4.9 \%$; 'time $=0$ '), stress induced a significant increase in corticosterone levels for $90 \mathrm{~min}(129.4 . \pm 19.6 \%$; $t=2.49$; $p \leq 0.05)$ and $105 \mathrm{~min}(165.0 \pm 19.2 \% ; t=3.82 ; p \leq 0.01)$. Furthermore, the highest difference was observed $105 \mathrm{~min}$ after stress administration.

Stress-induced plasma corticosterone rise. ANOVA showed a significant global between-groups difference $(\mathrm{F}(6,22)=8.83 ; p<0.001$; see Figure $2 \mathrm{~b})$. More specifically, stress induced a significant increase of plasma corticosterone 

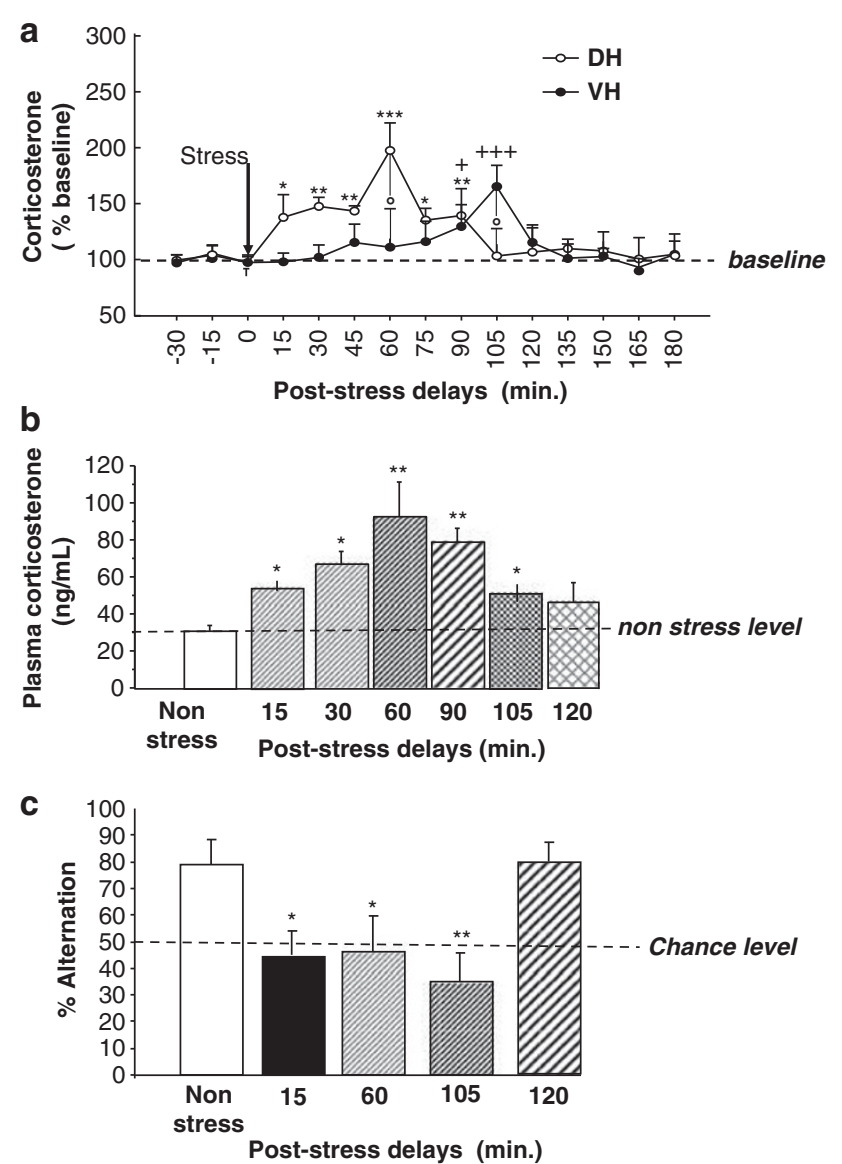

Figure 2 (a) Time-course evolutions of stress-induced corticosterone in the dorsal $(\mathrm{DH})$ and ventral $(\mathrm{VH})$ hippocampus measured by microdialysis in the same animal. In the $\mathrm{DH}$, the corticosterone rise is significant at the I5-min post-stress delay. The maximum corticosterone concentration occurred at $60 \mathrm{~min}$ post-stress delay with a return to baseline level $105 \mathrm{~min}$ after stress delivery. In $\mathrm{VH}$, a significant corticosterone rise is observed at the 90-min post-stress delay, and the maximum corticosterone concentration is measured 105 min after stress delivery with a return to baseline at $120 \mathrm{~min}$. Results are expressed in relative concentrations. Comparisons with baseline: for the $\mathrm{DH}$ : *p $<0.05$; $* * 2<0.0 \mathrm{l}$; *** $p<0.00$ I; for the $\mathrm{VH}$ : ${ }^{+} p<0.05 ;{ }^{+}+{ }^{+} p<0.00$ I; between group comparisons: $0-p<0.05$; (b) Plasma corticosterone concentrations $(\mathrm{ng} / \mathrm{ml})$ at different post-stress delays were measured in independent groups of mice. Plasma corticosterone concentrations are significantly increased from 15 to 105 min after stress with a maximum corticosterone concentration at the 60 -min post-stress delay. ${ }^{*} p<0.05$; $*$ * $p<0.0$ I as compared with the non-stressed animals. (c): Effect of stress on delayed alternation performance at several post-stress delays. Stress significantly decreases alternation rates from 15 to 105 min after delivery, whereas no deficit was observed at the 120-min post-stress delay. Comparison with non-stressed group: ${ }^{*} p<0.05$; $* * * 0.01$.

level at the post-stress delays of $15 \min (53.8 \pm 2.4 \mathrm{ng} / \mathrm{ml}$; $p<0.05)$, $30 \mathrm{~min}(66.6 \pm 7.0 \mathrm{ng} / \mathrm{ml} ; p<0.05), 60 \mathrm{~min}(92.2 \pm$ $19.7 \mathrm{ng} / \mathrm{ml} ; p<0.01), 90 \mathrm{~min}(78.5 \pm 7.6 \mathrm{ng} / \mathrm{ml} ; p<0.01)$, and at $105 \mathrm{~min}(50.3 \pm 0.65 \mathrm{ng} / \mathrm{ml} ; p<0.05)$ as compared with non-stressed animals $(30.3 \pm 3.6 \mathrm{ng} / \mathrm{ml})$. By contrast, the increase in corticosterone at the $120 \mathrm{~min}(46.2 \pm 7.6 \mathrm{ng} / \mathrm{ml}$; NS) post-stress delay was not significantly different from non-stressed mice.

Effects of acute stress delivered 15, 60, 105, and $120 \mathrm{~min}$ before memory testing on alternation performance. Data are represented in Figure 2c. The data revealed a significant

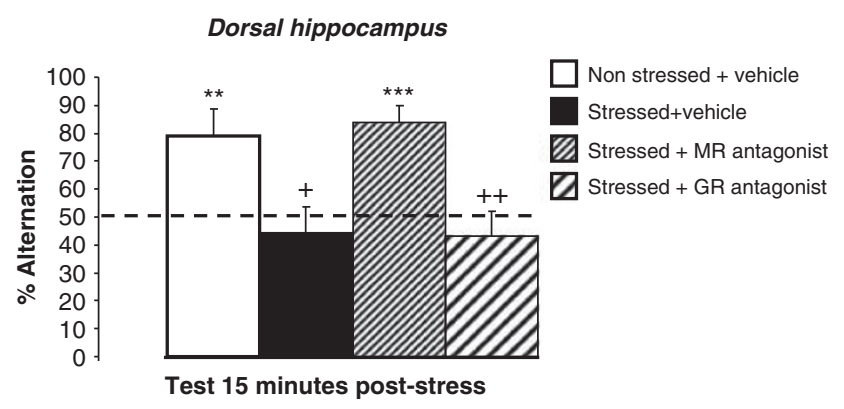

Figure 3 Effect of GR antagonist (RU-38486 or mifepristone) and MR antagonist (RU-28318 or oxprenoate) injections into the $\mathrm{DH}$ on delayed alternation performance in stressed mice tested 15 min after stress delivery. The doses of antagonists were selected according to a previous study (Dorey et al, 20 I I). The antagonists were bilaterally injected I $5 \mathrm{~min}$ before stress and $30 \mathrm{~min}$ before the test session. Control groups received the vehicle solution. As can be observed, the MR but not GR antagonist reversed the stress-induced decrease of alternation rates. Comparisons with non-stressed vehicles; ${ }^{+} p<0.05 ;{ }^{+}+p<0.0$ I; Comparisons with chance level (50\%): *** $<0.01$; $* * * * 0<0.001$.

between-group difference $(\mathrm{F}(4,90)=6.2 ; p=0.017)$. More precisely, non-stressed mice $(n=19)$ exhibited alternation rates $(79.1 \pm 9.8 \%)$ significantly above those observed in stressed ones tested $15 \mathrm{~min}$ after stress $(n=20 ; 44.4 \pm 8.9 ; \%$; $p<0.05), 60$ min after stress $(n=18 ; 46.2 \pm 13.3 ; p<0.05)$, and $105 \mathrm{~min}$ after stress $(n=20 ; 35.1 \pm 10.7 \%$; $p<0.01)$. By contrast, stressed mice tested $120 \mathrm{~min}$ after stress exhibit performance similar to those of non-stressed ones $(n=18$; $79.1 \pm 7.6 \%$; NS). Only the non-stressed and stressed $120 \mathrm{~min}$ groups differed significantly from chance level (50\%; $p<0.01$ in each comparison.)

All the groups exhibited similar short-term alternation rates evaluated $30 \mathrm{~s}$ after the delayed test session $(92.0 \pm 5.5 \%, 85.6 \pm 6.4,90.7 \pm 6.8,92.1 \pm 4.9$, and $87.4 \pm 5.8$ for the non-stressed and stressed groups at 15, 60, 105, and 120 min, respectively; $F<1.0$ ).

\section{Second Experiment: Effects of Intra-DH or VH Antagonists Injections on Delayed Alternation Rates}

Effects of $M R$ and GR antagonists injections in $D H$ at 15 min post-stress delay. Data are presented in Figure 3. The data revealed a significant between-group difference $(\mathrm{F}(3,68)=6.3 ; p<0.01)$. More precisely, the non-stressed + vehicle group exhibited significant higher alternation rates ( $n=19 ; 78.8 \pm 10.0 \%)$ as compared with the performance of the stressed + vehicle group $(n=18 ; 44.7 \pm 8.8 \% ; p<0.05)$ and as compared with that of the stressed animals receiving the GR antagonist $(n=19 ; 43.5 \pm 8.8 \% ; p<0.01)$. By contrast, they did not differe from the stressed animals receiving the MR antagonist ( $n=16 ; 84.1 \pm 5.9 \%$; NS). Only the non-stressed + vehicle and stressed $+M R$ antagonist groups differed significantly from chance level (50\%; $p<0.01$ and 0.001 , respectively).

All groups exhibited similar short-term alternation rates evaluated $30 \mathrm{~s}$ after the $24 \mathrm{~h}$ delayed test session $(82.0 \pm$ $5.3 \%, 79.0 \pm 4.7 \%, 85.2 \pm 7.1$, and $84.3 \pm 6.8 \%$, respectively, for the non-stressed + vehicle, stressed + vehicle, stressed + MR antagonist, and stressed + GR antagonist groups, respectively; NS in all comparisons). 
a
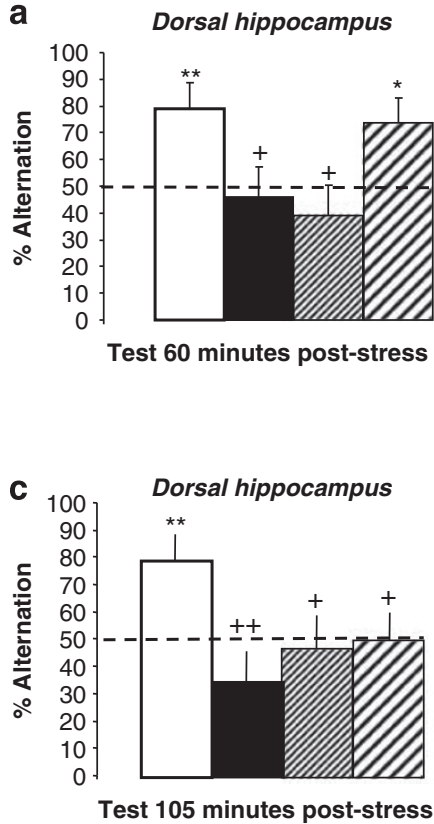

b

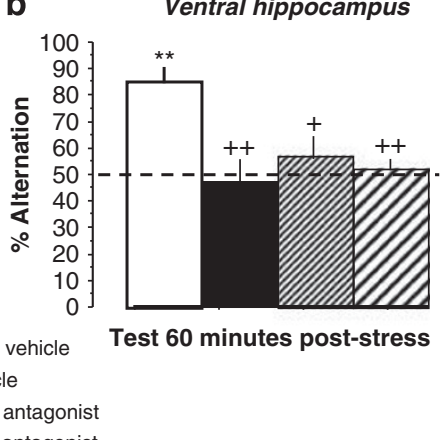

d

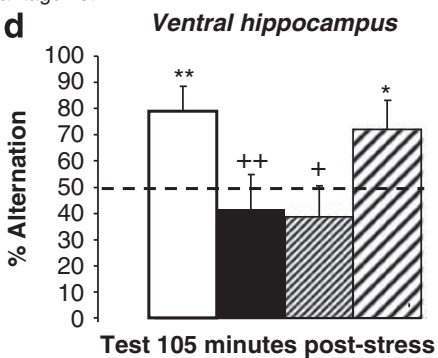

Figure 4 Effects of GR antagonist (RU-38486 or mifepristone) and MR antagonist (RU-283 I 8 or oxprenoate) injections into the DH or VH on delayed alternation rates at 60 and 105 min post-stress delays. In all experiments described in Figure 4a-d, both MR and GR antagonists were bilaterally injected at the dose of $20 \mathrm{mg} / \mathrm{ml} 15 \mathrm{~min}$ before stress and $30 \mathrm{~min}$ before behavioral testing. (a) Injections into the DH, test at 60 min post-stress: control groups' animals received the vehicle solution. The administration of GR but not of MR antagonist reversed the stress-induced alternation deficit as compared to vehicle. (b) Injections into the $\mathrm{VH}$, test at 60 min post-stress: the same injections and doses of MR and GR antagonists did not reverse the stress-induced memory impairments as compared with vehicle. (c) Injections into the DH, test at 105 min post-stress: both MR and GR antagonists did not reverse the stressinduced memory impairments as compared with vehicles; (d) injections into the $\mathrm{VH}$, test at 105 min post-stress. The administration of GR but not of MR antagonist reversed the stress-induced alternation deficit as compared with vehicle. (a-d) Comparisons with non-stressed vehicle: ${ }^{+} p<0.05 ;{ }^{++} p<0.0$ I; comparisons with chance level (50\%): $* 0<0.05$; $* * 0.01$.

\section{Effects of MR and GR Antagonists Injections in the DH and $\mathrm{VH}$ at 60 min Post-stress Delay}

Dorsal hippocampus. Data are presented in Figure 4a. The data revealed a significant between-group difference $(\mathrm{F}(3,72)=7.1 ; p<0.01)$. More precisely, the non-stressed + vehicle group exhibited significant higher alternation rates $(n=18 ; 77.9 \pm 9.6 \%)$ as compared with the performance of stressed + vehicle group $(n=18 ; 45.9 \pm 11.0 \% ; p<0.05)$ and as compared with the stressed animals receiving the MR antagonist $(n=20 ; 39.2 \pm 11.0 \% ; p<0.05)$. By contrast, they did not differ from the stressed animals receiving the GR antagonist $(n=20 ; 73.2 \pm 9.6 \%$; NS). Only the nonstressed + vehicle and stressed + GR antagonist groups differed significantly as compared with chance level (50\%; $p<0.01$ and 0.05 , respectively).

All groups exhibited similar short-term alternation rates evaluated $30 \mathrm{~s}$ after the $24 \mathrm{~h}$ delayed test session $(82.5 \pm$ $6.3 \%, 81.0 .0 \pm 8.5 \%, 77.5 \pm 10.8 \%$, and $86.7 \pm 7.3 \%$, respectively, for the non-stressed + vehicle, stressed + vehicle, stressed $+M R$ antagonist, and stressed $+\mathrm{GR}$ antagonist groups, respectively; NS in all comparisons).

Ventral hippocampus. Data are presented in Figure $4 \mathrm{~b}$. The data show that the injection of either the MR or GR antagonist was unable to restore memory performance in stressed animals.

The data revealed a significant between-group difference $(\mathrm{F}(3,66)=5.7 ; p<0.001)$. More precisely, the non-stressed + vehicle group exhibited significant higher alternation rates $(n=17 ; 85.3 \pm 5.6 \%)$ as compared with the performance of the stressed + vehicle group $(n=15 ; 46.6 \pm 9.0 \% ; p<0.01)$ and as compared with the stressed animals receiving the MR antagonist $(n=17 ; 55.8 \pm 8.4 \%$; $p<0.05)$ or the GR antagonist $(n=21 ; 52.3 \pm 5.4 \% ; p<0.01)$. Only the non-stressed + vehicle group differed significantly as compared with chance level $(50 \% ; p<0.01)$.

All groups exhibited similar short-term alternation rates evaluated $30 \mathrm{~s}$ after the $24 \mathrm{~h}$ delayed test session $(90.8 \pm 4.3 \%, 87.6 .0 \pm 8.1 \%, 83.2 \pm 6.9 \%$, and $89.7 \pm 5.9 \%$, respectively, for the non-stressed + vehicle, stressed + vehicle, stressed $+M R$ antagonist, and stressed + GR antagonist groups, respectively; NS in all comparisons).

\section{Effects of MR and GR Antagonists Injections in the DH and VH at 105 min Post-stress Delay}

Dorsal Hippocampus. Data are presented in Figure 4c. The data revealed a significant between-group difference $(\mathrm{F}(3,72)=6.2 ; p<0.05)$. More precisely, the non-stressed + vehicle group exhibited significant higher alternation rates $(n=20 ; 79.0 \pm 10.2 \%)$ as compared with the performance of the stressed + vehicle group $(n=19 ; 35.0 \pm 10.8 \% ; p<0.01)$ and as compared with the stressed animals receiving the MR antagonist $(n=18 ; 46.5 \pm 12.7 \% ; p<0.05)$ and also as compared with the stressed animals receiving the GR antagonist $(n=18 ; 49.7 \pm 10.3 \% ; p<0.05)$. Only the nonstressed + vehicle group differed significantly as compared with chance level $(50 \% ; p<0.01)$.

All groups exhibited similar short-term alternation rates evaluated $30 \mathrm{~s}$ after the $24 \mathrm{~h}$ delayed test session $(91.5 \pm 6.2 \%, 79.6 \pm 5.6 \%, 76.6 \pm 9.7 \%$, and $87.3 \pm 6.1 \%$, 

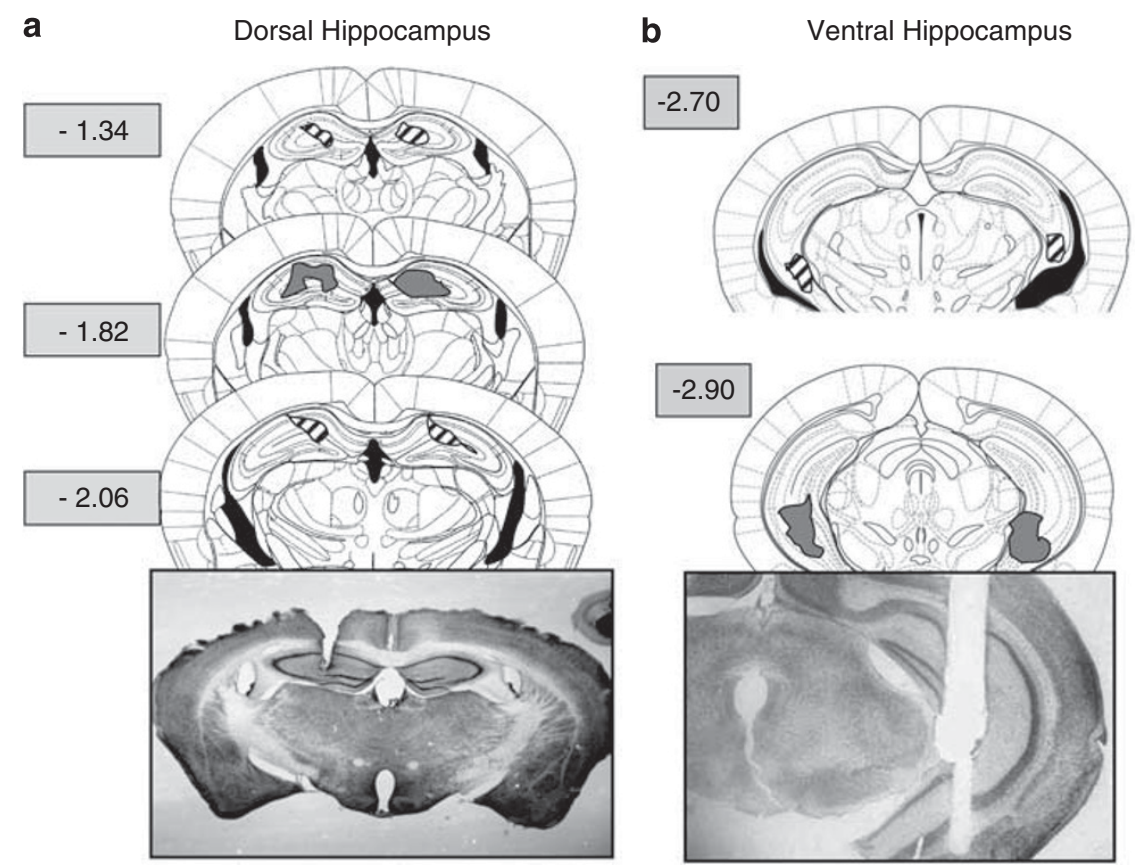

Figure 5 Representative localization of the microdialysis probes into the dorsal and ventral hippocampus in mice of Experiment I. (a and b) Reconstruction of the antero-posterior extent of probe locations (gray area: main sites; hashed areas: antero-posterior extent from the main site) Stereotaxic rostro-caudal coordinates are expressed in $\mathrm{mm}$ from bregma. Photomicrographs illustrate the location of the microdialysis probes in the dorsal and ventral hippocampus.

respectively, for the non-stressed + vehicle, stressed + vehicle, stressed $+M R$ antagonist, and stressed + GR antagonist groups, respectively; NS in all comparisons).

Ventral Hippocampus. Data are presented in Figure 4d. The data revealed a significant between-group difference $(\mathrm{F}(3,72)=9.2 ; p<0.01)$. More precisely, the non-stressed + vehicle group exhibited significant higher alternation rates $(n=19 ; 77.1 \pm 8.3 \%)$ as compared with the performance of the stressed + vehicle group $(n=20 ; 40.8 \pm 6.8 \% ; p<0.01)$ and as compared with the stressed animals receiving the MR antagonist $(n=18 ; 39.1 \pm 11.8 \% ; p<0.05)$ but not as compared with the stressed animals receiving the GR antagonist $(n=18 ; 72.3 \pm 10.9 \%$; NS). Only the nonstressed + vehicle group and the stressed $+\mathrm{GR}$ antagonist group differed significantly as compared with chance level (50\%; $p<0.01$ and $p<0.05)$.

All the four groups exhibited similar short-term alternation rates evaluated $30 \mathrm{~s}$ after the $24 \mathrm{~h}$ delayed test session $(\mathrm{F}(3,73)<1.0 ; \mathrm{NS})$.

\section{Histological Analyses}

Figures 5 and 6 show the anterograde extent and the localization of the cannulae tips in the $\mathrm{DH}$ and $\mathrm{VH}$ of mice submitted either to the microdialysis (Figure 5) or to the pharmacological (Figure 6) experiments. Gray zones: main implantation sites; black hashed areas: antero-retrograde extent of the cannulae tips implantation.

\section{DISCUSSION}

The main findings of the study are summarized in Figure 7.
In the first experiment, we evidenced that an acute stress (electric footshocks) induced in the $\mathrm{DH}$ then in the $\mathrm{VH}$ a corticosterone rise measured by microdialysis. Indeed, we showed that the maximum corticosterone concentration in VH occurred $45 \mathrm{~min}$ later (105 min post-stress) as compared with the DH (60 min post-stress). On the other hand, we also observed a concomitant memory retrieval impairment in a non-rewarded delayed alternation task. Indeed, we found that stress-induced memory deficits occurred between 15 and $105 \mathrm{~min}$, but were no longer observed at the 120-min post-stress delay. Thus, one of the main results of the study is that, at least up to the 60 -min post-stress delay interval, the memory deficit does not depend on corticosterone rise into the $\mathrm{VH}$. In the second experiment, we showed that the stress-induced memory deficit observed 15 min after stress was antagonized by injections of MR but not of GR antagonists (RU-28318 and RU-38486, respectively) in the $\mathrm{DH}$. By contrast, with a 60 -min post-stress delay, the GR but not the MR antagonist alleviated the memory impairment. However, both antagonists injected into the $\mathrm{DH}$ failed to restore memory performance at the 105-min post-stress delay. In addition, injections of the GR but not the MR antagonist into the VH blocked the stressinduced memory impairment observed at the 105 -min poststress delay.

From these data, two main questions arise: (i) what is the relative contribution of the time-dependent regional involvement of the $\mathrm{DH}$ and $\mathrm{VH}$ in the stress-induced memory deficits? (ii) What are the mechanisms underlying the sequential involvement of MR and GR within the HPC?

As regards the first issue, behavioral results obtained in the first experiment show that the time-course evolution of the memory impairments is concomitant with the stressinduced corticosterone rise within the $\mathrm{DH}$ and $\mathrm{VH}$. Indeed, 
a

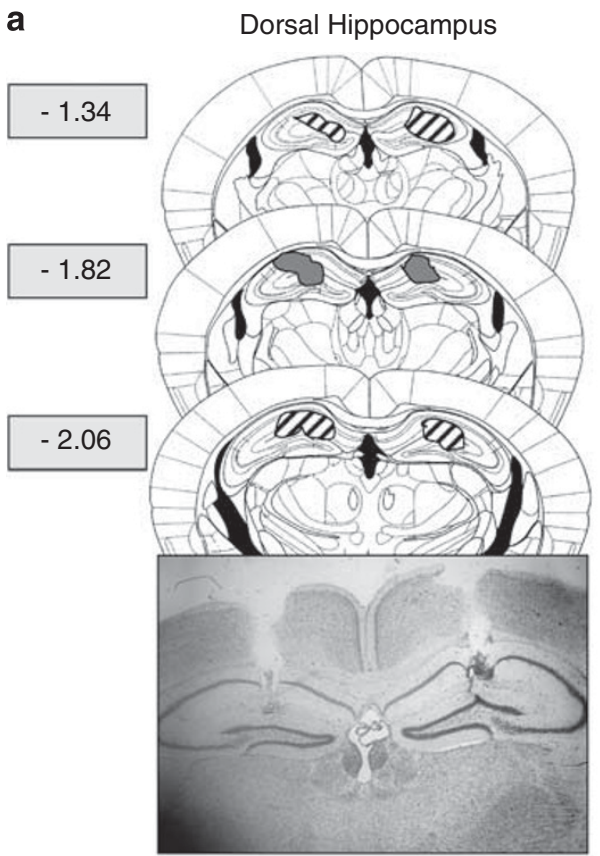

b Ventral Hippocampus
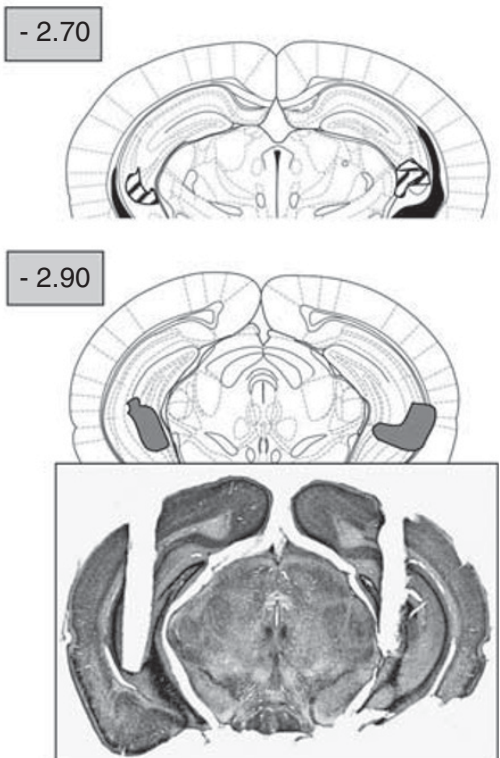

Figure 6 Representative localization of the cannulae into the dorsal and ventral hippocampus in mice of Experiment 2. (a and b) Reconstruction of the antero-posterior extent of the sites (gray area: main sites; hashed areas: antero-posterior extent from the main sites). Stereotaxic rostro-caudal coordinates are expressed in $\mathrm{mm}$ from bregma. Photomicrographs illustrate the location of the cannulae in the dorsal and ventral hippocampus.

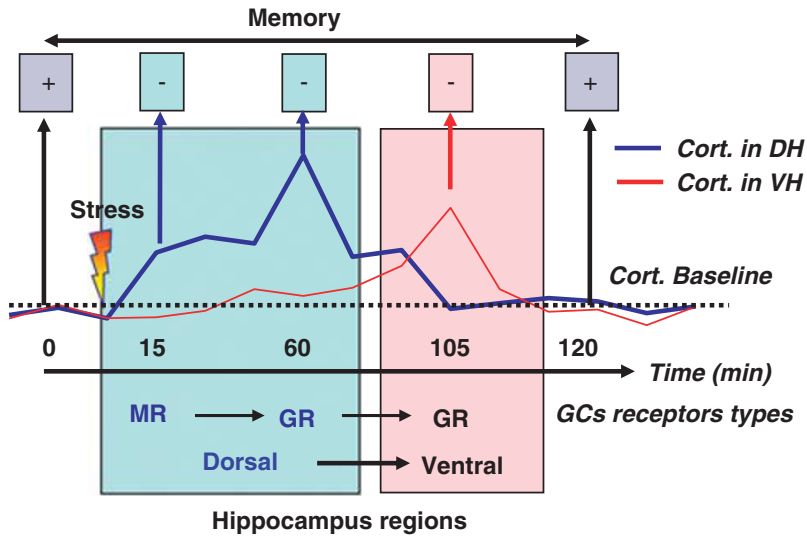

Figure 7 Synoptic representation of the main findings of the study. This figure points out a triple dissociation as regards the time-course involvement of the hippocampus regions, corticosterone rises and glucocorticoid receptor types in relation with memory retrieval impairments after acute stress.

the findings drawn from microdialysis are congruent with our prvious studies showing that memory retrieval impairments are associated to the $\mathrm{DH}$ corticosterone rise 15 but not 120 min after acute stress delivery (Chauveau et al, 2010; Tronche et al, 2010; Dorey et al, 2011). Surprisingly, however, data of the present study show that the stressinduced memory deficit observed from 15 to 60 min poststress delays does not depend on the $\mathrm{VH}$ as corticosterone concentrations in the $\mathrm{VH}$ are not different from baseline for this time-window. By contrast, the memory deficit observed at the 105-min post-stress delay seems to depend on the maximum corticosterone level observed in the $\mathrm{VH}$, insofar as corticosterone concentrations in the DH are not different from baseline at this delay. Thus, the different time-course evolutions of corticosterone in the $\mathrm{DH}$ and $\mathrm{VH}$ could reflect a sequential involvement of both the HPC regions in the observed time-dependent stress-induced memory deficits. Such a view is also strengthened by the observations that GR antagonist administered in the DH is efficient at the 60min post-stress delay, whereas inefficient when administered in the VH at the same delay. On the contrary, the GR antagonist administered in the VH is efficient at the 105min post-stress delay, whereas being without effect when administered in the DH at the same delay.

Finally, from a functional point of view, our present data point out a temporal and spatial dissociation on stressinduced corticosterone rise and retrieval memory impairments.

It remains, however, to understand the mechanisms sustaining the emergence of the different time-course evolutions of corticosterone in the DH and VH after stress. Previous data from our team already evidenced the peripheral origin of corticosterone in the $\mathrm{DH}$ after stress. Indeed, we showed that systemic administration of metyrapone (an inhibitor of corticosterone synthesis) blocked the stress-induced rise of corticosterone in the $\mathrm{DH}$ (Chauveau et al, 2010) and that mice deprived of corticosteronebinding globuline $\left(\mathrm{CBG}^{-} /^{-} \mathrm{KO}\right.$ mice) did not show any stress-induced corticosterone rise in the DH (Minni et al, 2012). In the present study, plasma and HPC corticosterone were measured in independent groups to avoid blood sampling stress, which could induce biases on HPC corticosterone quantification. We found that the maximum plasma corticosterone value occurring at $60 \mathrm{~min}$ after stress is in phase with the one observed in the $\mathrm{DH}$, but not with the one observed in the VH (105 min post-stress). Given that, we could formulate the hypothesis of a diffusion of corticosterone from the $\mathrm{DH}$ to $\mathrm{VH}$ via a mechanism 
remaining to be determined. For this purpose, we intend to lesion or inactivate the $\mathrm{DH}$ to investigate its role in the delayed corticosterone rise within the $\mathrm{VH}$ after stress.

From a functional point of view, it has been proposed that an acute stress would induce a disconnection between the $\mathrm{DH}$ and $\mathrm{VH}$ and so far could spare or even increase the functional activity of the $\mathrm{VH}$ and its main brain targets involved in emotional processes (amygdala and hypothalamus) (Segal et al, 2010). Our data are in agreement with this hypothesis, as the maximum corticosterone concentrations emerged at different post-stress delays in the $\mathrm{DH}$ and $\mathrm{VH}$. This suggests a different time-dependent involvement of both the HPC regions in the stress-induced memory deficits. According to our data, however, memory functions sustained by the DH are first affected by the acute stress. Indeed, in the present study, delayed alternation deficits are related to the earlier stress-induced corticosterone rise within the $\mathrm{DH}$, then in the $\mathrm{VH}$. This result is in agreement with previous studies from our group showing that an acute stress delivered $15 \mathrm{~min}$ before testing produced memory retrieval impairments in a serial discrimination task. Indeed, we found that the deficit was observed specifically for the information sustained by the $\mathrm{DH}$, whereas the information sustained by the BLA-frontal cortex pathway (heavily connected with the $\mathrm{VH}$ ) was unaffected (Chauveau et al, 2008, 2009, 2010). Furthermore, the presently observed late involvement of the $\mathrm{VH}$ following acute stress is in agreement with relevant studies indicating that the $\mathrm{DH}$ would be much more involved in processing cognitive information, whereas the $\mathrm{VH}$ has a key role in late consolidation of emotional memory and/or anterograde memory processes (Segal et al, 2010; Fanselow and Dong, 2010).

Even though speculative, we suggest that the late corticosterone rise into the $\mathrm{VH}$ could have a major role on anterograde memory processes and more particularly in the consolidation of emotional and/or traumatic memory. Indeed, according to our data, one can hypothesize that the delayed $\mathrm{VH}$ activation via GR receptors could be of importance for the establishment of long-term memory or even that excessive $\mathrm{VH}$ activation contributes to the development of PTSD. Thus, GR antagonists could be a relevant pharmacological perspective to avoid consolidation or reconsolidation of traumatic events (see Bonne et al, 2004). So far, in further studies using animal models of PTSD, we intend to test such drugs in the VH-dependent emotional memory tasks, i.e. fear conditioning (McEown and Treit, 2009).

As regards the second issue, i.e. the mechanisms underlying the sequential involvement of MR and GR within the HPC, we show that the rapid ( $15 \mathrm{~min}$ ) deleterious effects of stress on memory involved first the MR but not GR receptors in the $\mathrm{DH}$. This result confirms our previous finding (Dorey et al, 2011). In addition, lengthening the post-stress delay from 15 to $60 \mathrm{~min}$ involves GR but no longer MR in so far as only the GR antagonist is efficient to suppress memory impairments. The lack of memory effects of the MR antagonist at the 60- and 105-min delays cannot be explained by the fact that the MR antagonist is no longer bound to their receptors. Indeed, Kim et al (1998) already reported that the in vivo $\mathrm{MR}$ receptor occupancy by $\mathrm{RU}$ 28318 was still observed in the rat HPC up to $2 \mathrm{~h}$ after systemic injection.
The sequential activation of MR then of GR is in agreement with the view that the rapid stress response involves first MR (Dorey et al, 2011) and excitatory neurotransmitter receptors trafficking through GC action (Groc et al, 2008; Chaouloff and Groc 2011,) which contribute to the rapid effect of GCs on memory. GC-glutamatergic interactions have been proposed to explain many of the diverse actions of GCs on cognition (Conboy and Sandi, 2010; Sandi, 2011). Furthermore, it has been suggested that NMDA receptors would be at the interface between cognition and emotion in both the hippocampal zones (Barkus et al, 2010).

For longer delays, GCs act via a classic genomic action sustained by GR (Joëls, 2008). Moreover, given the high and low affinity of MR and GR for GCs, respectively, the sequential activation of these receptors could depend on the hormone concentration at the time of memory testing after stress. However, electrophysiological data, indicating that stress can also activate simultaneously GR and MR in different parts of the HPC, have challenged the widely accepted model, which suggests a time- and dose-dependent effect of steroid hormones on cellular functions in the HPC. Indeed, as shown by relevant studies on the interaction between LTP and LTD regulation, corticosteroid modulation of synaptic plasticity in the HPC is a complex process involving differential activation of $\mathrm{MR}$ and GR within the $\mathrm{DH}$ and VH (see in Segal et al, 2010; Maggio and Segal, 2012). Nevertheless, our present data agreed overall with the view developed by Maggio and Segal (2012), suggesting that steroid hormones act as molecular switches: by changing the strength of synaptic connectivity in the HPC following stress, they regulate the routes by which the HPC is functionally linked to the rest of the brain. Indeed, our present data show that along with synaptic and molecular mechanisms induced by stress, the different time-course evolutions of corticosterone rises after stress in the $\mathrm{DH}$ and $\mathrm{VH}$ contribute to the functional switch from the $\mathrm{DH}$ to the VH. Indeed, MR are first involved at the 15-min post-stress delay when corticosterone concentration is low in the $\mathrm{DH}$, whereas GR are activated when corticosterone concentration is higher i.e. at 60 min post-stress delay first in the $\mathrm{DH}$ and then at $105 \mathrm{~min}$ post-stress delay in the $\mathrm{VH}$.

In conclusion, our study using a dynamic approach of the time-course evolution of corticosterone levels evidenced that stress impairs HPC -dependent memory retrieval via a mechanism dependent on post-stress delays (from 15 to $105 \mathrm{~min}$ ), areas (DH vs $\mathrm{VH}$ ), and of GC receptor types (MR $v s$ GR). Such a triple dissociation emphasizes the complexity of the stress-memory interaction, particularly as regards the relationships between the $\mathrm{DH}$ and $\mathrm{VH}$.

\section{ACKNOWLEDGEMENTS}

This research was supported by the CNRS and by a grant (Opération $\mathrm{n}^{\circ}$ 03co015-05 - PEA 010801) from DGA/DET/ SCET/CEP/SHP, Paris, France. We also thank Nadia Henkous for her help in corticosterone dosages and Laurence Decorte for her help in histological analyses. This work has benefited from the facilities and expertise of the imagery platform Imag'In (www.incia.u-bordeaux1.fr) which is supported by CNRS and Région Aquitaine. We also 
like to thank Dr. Frances Ash for language proofreading (contact: ashberac@free.fr).

\section{DISCLOSURE}

We wish to extend the following statements: except for income received from primary employers, no financial support nor any compensation has been received from either any individual or corporate entity over the past 3 years for either research or professional service in relation with this study. Further, no single personal financial holding may exist nor be perceived as constituting a potential conflict of interest.

\section{REFERENCES}

Barkus C, McHugh SB, Sprengel R, Seeburg PH, Rawlins JN, Bannerman DM (2010). Hippocampal NMDA receptors and anxiety: at the interface between emotion and cognition. Eur $J$ Pharmacol 626: 49-56.

Bonne O, Grillon C, Vythilingam M, Neumeister A, Charney DS (2004). Adaptive and maladaptive psychobiological responses to severe psychological stress: implications for the discovery of novel pharmacotherapy. Neurosci Biobehav Rev 28: 65-94.

Borski RJ (2000). Nongenomic membrane actions of glucocorticoids in vertebrates. Trends Endocrinol Metab 11: 427-436.

Breuner CW, Greenberg AL, Wingfield JC (1998). Noninvasive corticosterone treatment rapidly increases activity in Gambel's white-crowned sparrows (Zonotrichia leucophrys gambelii). Gen Comp Endocrinol 111: 386-394.

Chaouloff F, Groc L (2011). Temporal modulation of hippocampal excitatory transmission by corticosteroids and stress. Front Neuroendocrinol 1: 25-42.

Chauveau F, Piérard C, Coutan M, Drouet I, Liscia P, Béracochéa D (2008). Prefrontal cortex or basolateral amygdala lesions blocked the stress-induced inversion of serial memory retrieval pattern in mice. Neurobiol Learn Mem 2: 395-403.

Chauveau F, Piérard C, Tronche C, Coutan M, Drouet I, Liscia P et al (2009). The hippocampus and prefrontal cortex are differentially involved in serial memory retrieval in non-stress and stress conditions. Neurobiol Learn Mem 91: 447-455.

Chauveau F, Tronche C, Piérard C, Liscia P, Drouet I, Coutan M et al (2010). Rapid stress-induced corticosterone rise in the hippocampus reverses serial memory retrieval pattern. Hippocampus 1: 196-207.

Conboy L, Sandi C (2010). Stress at learning facilitates memory formation by regulating AMPA receptor trafficking through a glucocorticoid action. Neuropsychopharmacology 35: 674-685.

Dallman MF (2005). Fast glucocorticoid actions on brain: back to the future. Front Neuroendocrinol 26: 103-108.

De Kloet ER, Reul JM, de Ronde FS, Bloemers M, Ratka A (1986). Function and plasticity of brain corticosteroid receptor systems: action of neuropeptides. J Steroid Biochem 5B: 723-731.

De Kloet ER, Oitzl MS, Joels M (1999). Stress and cognition: are corticosteroids good or bad guys? Trends Neurosci 22: 422-426.

De Quervain DJ, Roozendaal B, McGaugh JL (1998). Stress and glucocorticoids impair retrieval of long-term spatial memory. Nature 394: 787-790.

Donley MP, Schulkin J, Rosen JB (2005). Glucocorticoid receptor antagonism in the basolateral amygdala and ventral hippocampus interferes with long-term memory of contextual fear. Behav Brain Res 164: 197-205.

Dorey R, Piérard C, Shinkaruk S, Tronche C, Chauveau F, Baudonnat $\mathrm{M}$ et al (2011). Membrane mineralocorticoid but not glucocorticoid receptors of the dorsal hippocampus mediate the rapid effects of corticosterone on memory retrieval. Neuropsychopharmacology 36: 2639-2649.

Falkenstein E, Tillmann HC, Christ M, Feuring M, Wehling M (2000). Multiple actions of steroid hormones-a focus on rapid, nongenomic effects. Pharmacol Rev 52: 513-556.

Fanselow MS, Dong HW (2010). Are the dorsal and ventral hippocampus functionally distinct structures? Neuron 65: 7-19.

Ferguson D, Sapolsky R (2007). Mineralocorticoid receptor overexpression differentially modulates specific phases of spatial and nonspatial memory. J Neurosci 27: 8046-8052.

Groc L, Choquet D, Chaouloff F (2008). The stress hormone corticosterone conditions AMPAR surface trafficking and synaptic potentiation. Nat Neurosci 8: 868-870.

Joëls M (2008). Functional actions of corticosteroids in the hippocampus. Eur J Pharmacol 583: 312-321.

Joëls M, Baram TZ (2009). The neuro-symphony of stress. Nat Rev Neurosci 10: 459-466.

Joëls M, Karst H, DeRijk R, De Kloet ER (2008). The coming out of the brain mineralocorticoid receptor. Trends Neurosci 31: $1-7$.

Joëls M, Pu Z, Wiegert O, Oitzl MS, Krugers HJ (2006). Learning under stress: how does it work? Trends Cogn Sci 10: $152-158$.

Joëls M, Karst H, Krugers HJ, Lucassen PJ (2007). Chronic stress: implications for neuronal morphology, function and neurogenesis. Front Neuroendocrinol 28: 72-96.

Khaksari M, Rashidy-Pour A, Vafei AA (2007). Central mineralocorticoid receptors are indispensable for corticosteroneinduced impairment of memory retrieval. Neuroscience 149: 729-738.

Kim PJ, Cole MA, Kalman BA, Spencer RL (1998). Evaluation of RU28318 and RU40555 as selective mineralocorticoid receptor and glucocorticoid receptor antagonists, respectively: receptor measures and functional studies. J Steroid Biochem Molec Biol 67: 213-222.

Kim JJ, Diamond DM (2002). The stressed hippocampus, synaptic plasticity and lost memories. Nature Rev Neurosci 3: 453-462.

Linthorst ACE, Reul JM (2008). Stress and the brain: Solving the puzzle using microdialysis. Pharmacol Biochem Behav 90: 163-173.

Lu NZ, Wardell SE, Burnstein KL, Defranco D, Fuller PJ, Giguere V et al (2006). The pharmacology and classification of the nuclear receptor superfamily: glucocorticoid, mineralocorticoid, progesterone, and androgen receptors. Pharmacol Rev 58: 782-797.

Lupien SJ, Lepage M (2001). Stress, memory, and the hippocampus: can't live with it, can't live without it. Behav Brain Res 127: $137-158$.

Makara GB, Haller J (2001). Non-genomic effects of glucocorticoids in the neural system. Evidence, mechanisms and implications. Prog Neurobiol 65: 367-390.

Maggio N, Segal M (2012). Steroid modulation of hippocampal plasticity: switching between cognitive and emotional memories. Front Cell Neurosci 6: 1-5.

McEown J, Treit D (2009). The role of the dorsal and ventral hippocampus in fear and memory of a shock-probe experience. Brain Res 1251: 185-194.

McEwen BS, Sapolsky RM (1995). Stress and cognitive function. Curr Opin Neurobiol 5: 205-216.

McGaugh JL, Roozendaal B (2002). Role of adrenal stress hormones in forming lasting memories in the brain. Curr Opin Neurobiol 12: 205-210.

McGaugh JL (2004). The amygdala modulates the consolidation of memories of emotionally arousing experiences. Annu Rev Neurosci 27: 1-28.

Minni A, Dorey R, Piérard C, Dominguez G, Helbling JC, Foury A et al (2012). Critical role of plasma corticosteroid-bindingglobulin to deliver glucocorticoids to the brain during stress: impact on memory retrieval, Endocrinology. submitted. 
Moser MB, Moser EI (1998). Functional differentiation in the hippocampus. Hippocampus 8: 608-619.

Naber PA, Witter MP (1998). Subicular efferents are organized mostly as parallel projections: A double-labeling, retrogradetracing study in the rat. J Comp Neurol 393: 284-297.

Orchinik M, Murray TF, Moore FL (1991). A corticosteroid receptor in neuronal membranes. Science 252: 1848-1851.

Paxinos G, Franklin KBJ (2001). The Mouse Brain in Stereotaxic Coordinates. 2nd edn. Academic Press: San Diego.

Pfaff DW, Silva MT, Weiss JM (1971). Telemetered recording of hormone effects on hippocampal neurons. Science 172: 394-395.

Revest JM, Kaouane N, Mondin M, Le Roux A, Rougé-Pont F, Vallée $\mathrm{M}$ et al (2010). The enhancement of stress-related memory by glucocorticoids depends on synapsin-Ia/Ib. Mol Psychiatry 1125: 1140-1151.

Reul JM, de Kloet ER (1985). Two receptor systems for corticosterone in rat brain: microdistribution and differential occupation. Endocrinology 117: 2505-2511.

Roozendaal B (2003). Systems mediating acute glucocorticoid effects on memory consolidation and retrieval. Prog Neuropsychopharmacol Biol Psychiatry 27: 1213-1223.

Sajadi AA, Samaei SA, Rashidy-Pour A (2006). Intra-hippocampal microinjections of anisomycin did not block glucocorticoidinduced impairment of memory retrieval in rats: an evidence for non-genomic effects of glucocorticoids. Behav Brain Res 173: $158-162$.

Sandi C, Venero C, Guaza C (1996). Novelty-related rapid locomotor effects of corticosterone in rats. Eur J Neurosci 8: 794-800.
Sandi C (2011). Glucocorticoids act on glutamatergic pathways to affect memory processes. TINS 34: 165-176.

Sapolsky RM, Romero LM, Munck AU (2000). How do glucocorticoids influence stress responses? Integrating permissive, suppressive, stimulatory, and preparative actions. Endocr Rev 21: 55-89.

Segal M, Richter-Levin G, Maggio N (2010). Stress-induced dynamic routing of hippocampal connectivity: a hypothesis. Hippocampus 12: 1332-1338.

Tasker JG, Di S, Malcher-Lopes R (2006). Minireview: rapid glucocorticoid signaling via membrane-associated receptors. Endocrinology 147: 5549-5556.

Tronche C, Piérard C, Coutan M, Chauveau F, Liscia P, Béracochéa D (2010). Increased stress-induced intra-hippocampus corticosterone rise associated with memory impairments in middle-aged mice. Neurobiol Learn Mem 3: 343-351.

Van Eekelen JA, Jiang W, De Kloet ER, Bohn MC (1988). Distribution of the mineralocorticoid and the glucocorticoid receptor mRNAs in the rat hippocampus. J Neurosci Res 21: 88-94.

Venero C, Borrell J (1999). Rapid glucocorticoid effects on excitatory amino acid levels in the hippocampus: a microdialysis study in freely moving rats. Eur J Neurosci 11: 2465-2473.

(c) This work is licensed under the Creative SoMERERHIS RESERVED Commons Attribution-NonCommercial-No
Derivative Works 3.0 Unported License. To view a copy of this license, visit http://creativecommons.org/licenses/by-nc-nd/3.0/ 